\title{
ONLINE TEACHING AND LEARNING PROJECT MANAGEMENT
}

\author{
Manouchehr Tabatabaei \\ Georgia Southern University \\ mtabatab@georgiasouthern.edu
}

\begin{abstract}
The number of project management courses in institutions of higher education is increasing to meet the high demand of effective project managers in organizations. Many institutions offer graduate degrees and certificates in project management. Therefore, more online courses in project management are offered in addition to the traditional mode of classroom setting. The purpose of this research is to present the challenges associated with teaching an online project management course, and discuss approaches to enhance learning. The need for a methodology is discussed and components of this methodology are identified for designing and delivering an effective online project management course. The suggested components of the methodology are based on the literature, best practices and experience of the course instructors. Two important propositions in the paper are: a different approach is necessary when teaching an online project management course, and teaching effective teamwork is a significant challenge in an online environment.
\end{abstract}

\section{Keywords}

Project Management, Online Course Design and Delivery, Teamwork, Virtual Team, Collaborative Learning Online

\section{INTRODUCTION}

The number of courses delivered online is substantially increasing every year, along with the number of online degrees (Allen \& Seaman, 2011; Tallent-Runnels et al., 2006). Allen and Seaman (2011) report on the growth of online enrollments in recent years, survey results of academic leaders of over 2,500 institutions of higher education which over $65 \%$ indicated online learning is a critical part of their long-term strategic plan. According to their report, the rate of growth in online enrollments is ten times that of the rate in all higher education and since 2003; online enrollments have grown by $358 \%$. The prediction is that there will be 22 million online students by 2014 with the size of market for online learning estimated to exceed 69 billion dollars by 2015 (Hezel Associates, 2005). Therefore, online education is a top priority of higher education in the 21 st century (Bagnato, 2004). The literature has covered a wide range of topics on online education which include advantages, disadvantages, quality, and how to deliver online courses (Bisoux, 2002; Granitz \& Greene, 2003; Hollenbeck, Zinkhan, \& French, 2005; Peltier, Schibrowsky, \& Drago, 2007; Smith, 2001). In addition, there is an ongoing debate as to the criteria to be used to determine what courses are more suitable to be offered online as well as ownership and uses of intellectual property created as an online course is developed (Ambient Insight, 2009; Ellin, 2000).

The planning and design of an online course should be different than the planning and design of the same course taught in the traditional classroom. This fact is often not understood and online courses are taught in the same way as traditional courses without finding more suitable designs to deliver courses in an online environment (Dolezalek, 2004).

The main issue teaching in online and offline environments is not teaching students face-to-face or not. It is rather, how to effectively use technology in online courses to design the course and deliver it to ensure student learning and accomplishing objectives of the course (Scardamalia \& Bereiter, 2006). Further, effectively choosing and encouraging use of technology to add value to the course. For example, increase student 
involvement by encouraging frequent participation using discussion boards. Also, improve collaboration and commination by setting up virtual teams to use collaboration and communication technologies.

In recent years, the importance of project management (PM) has significantly increased in industry and as the result the number of PM course offerings in higher education has increased. Organizations are interested more than ever in hiring graduates with a strong knowledge of project management and strong project management skills. This is mainly due to high rate of project failure in organizations. The Standish Group issued a popular report appropriately named the Chaos Report providing the results of a survey which gathered data on reasons for information technology project failures. This report provided an early warning on software project failures, $84 \%$ of software development projects fail (Chaos Report, 1995). Many institutions are now offering graduate and undergraduate project management courses to meet the high demand of organizations for effective project managers. Some institutions are also offering graduate certificates and a degree in project management. Many institutions have already started, or are planning, to deliver these courses online, in addition to the traditional classroom setting. In PM courses, communication, dialogue, critical thinking, problem-solving, and team building (often referred to as soft skills) are greatly emphasized, which creates a unique challenge in offering this course online. In order to face this unique challenge, a methodology is proposed to more effectively design and deliver an online PM course to take advantage of the opportunities online technology has presented. The purpose of this research is to emphasize differences between the design and delivery of an online PM course compared to a traditional offline PM course, and to demonstrate challenges including virtual teamwork in an online PM course. A methodology is presented for this purpose, and some potential components are introduced. The suggested components are based on the literature, best practices and the experience of the course instructors which should provide guidelines on how to plan, develop and deliver PM courses more effectively. The findings of this research should increase awareness of differences between the design and delivery of online and offline courses in general and the PM course in particular. Further, the findings provide guidelines for effective design and delivery of an online PM course. Pitfalls associated with teamwork co-located and virtual teams are presented and suggestions are made for more effective ways of teaching teamwork and how to make virtual teams more effective in an online PM course. It can be argued that teamwork can be removed from the requirements of the PM course. However, teamwork skill is greatly emphasized by the employers and accreditation bodies are encouraging teamwork component in the curriculum. The graduates are increasingly expected to work on projects as a team not only co-located, but also virtual teams as business globalization is emphasized. In fact, one of the main purposes of the PM is team building and teamwork.

\section{LITERATURE REVIEW}

There has been an extensive discussion on the challenges of offering online courses in general (Aggarwal \& Bento, 2000; Allen \& Seaman, 2006, 2011; Campbell, 2004; Cobb, 1980). The advantages and disadvantages of offering online courses are discussed and debated, and the quality of learning in an online environment has been questioned (Bernard, Abrami, Lou, \& Borokhovski, 2004; Borich, 2004; Coppola, Hiltz, \& Rotter, 2000; Sahin, 2006). The literature on online education has mainly focused on the effectiveness of online courses in terms of student learning. The consensus seems to be "no significant difference" (Murphy \& Cifunentes, 2002; Piccoli, Ahmad, \& Ives, 2001; Privateer, 1999; Sahin, 2006). The finding of no significant difference in student learning in online and offline courses is not an indication that learning outcomes are the same in online and offline courses (Piccoli et al., 2001).

Recently, attention is given to perceptions of online education in the job market by the recruiters and employers (Kohlmeyer, Seese, \& Sincich, 2011; Metrejean \& Noland, 2011; Tabatabaei \& Gardiner, 2012). Although, it seems mode of education is not a major factor in evaluating the candidates, but many still prefer candidates with traditional face-to-face education (Kohlmeyer et al., 2011).

More successful online courses appear to be content and material oriented (explicit knowledge) rather than skill and practice oriented (tacit knowledge). Courses emphasizing high levels of interaction and immediate feedback 
as part of skill and knowledge transfer appear to be poor candidates for online presentation due to the asynchronous nature of traditional online courses which emphasize text material as the communication method. However, there has been success with one-on-one skills training using video conferencing over the Internet (Campbell, 2004).

PM as a course in higher education, at both the undergraduate and graduate levels, is becoming a standard course offering for students in a range of disciplines including business, information systems and information technology. While the specific skills vary, there are a core set of PM skills and knowledge that is shared by most disciplines. This set of core skills and knowledge has been described by the Project Management Institute (PMI) as part of its continuing effort to create a professional project management community across the various disciplines and industries that use the role of project manager in their activities.

The primary goal of many PM courses is to expose students to professional PM practices by providing a survey of the PMI knowledge areas along with exposure to leadership and soft management skills. The objectives in a PM course typically include, not only teaching theory, terms, definitions and new concepts related to the subject, but also the transfer of new technical skills in using and applying specialized software as well as managerial skills dealing with people (interpersonal skills, communications theory, dialogue, critical thinking and analysis skills, leadership theory, organizational theory and team building). Most surveyed PM courses emphasize the following:

- How to identify and define tasks using a project planning paradigm.

- How to use a particular PM software application to create project timelines and schedules (GANTT charts) and Network and Critical Path Analysis charts (PERT. Program Evaluation and Review Techniques).

- How to use appropriate kinds of tasks and inter-task linkages.

- How to use the software application to update a project's PERT or GANTT charts as the project progresses, how to read the resulting charts and how to analyze the charts to develop changed project plans.

- How to develop "soft" managerial and leadership skills.

Most project managers have little legitimate power, relying on reward power, referent power, and expert power (Cobb, 1980). In order to manage a project to a successful conclusion, project managers must learn how to be effective leaders (see also Howard, 2002) for similar requirements for IS professionals, in general. The successful project manager has both explicit knowledge (Project Management Institute categorizing subject matter areas of the Project Management Body of Knowledge into nine areas), and tacit knowledge (the ability to apply the knowledge of these nine areas as the situation demands through the ability to empathize with and have insight into people). Most PM course objectives and desired learning outcomes go beyond the traditional objective of the student learning "about" the subject, an objective many online web courses have addressed successfully (Kamis \& $\mathrm{Kahn}, 2009)$. How to teach students the skills and behaviors needed to better communicate, manage, lead, work with people and teams are significant issues that need to be addressed. These interpersonal skill objectives make offering an online PM course a challenge. Therefore, a methodology is needed to design, plan and deliver an online PM course to overcome some of the problems and limitations of online delivery and to take advantage of some of the opportunities online technology can provide. Rossin, Ro, Klein, and Yi (2009) surveyed of literature on online teaching up to 2006 found that (1) courses designed and developed for in-class delivery were not necessarily suitable for the online environment and that (2) a methodology or model, based upon quality research, for online courses is needed.

\section{ONLINE COURSE DESIGN AND DEVELOPMENT METHODOLOGY}

A methodology for developing an online PM course would have many components in common with many other types of online courses. Many of the activities involved in any online course such as tests on content, discussion groups and submission of work products would be the same for a PM course. Since the course content involves 
soft skills, such as management and leadership, fruitful discussion forums can be created around the various topic areas allowing students to post comments, short essays and links to papers or articles on the web. The online platform provided by much course management software today, such as "Blackboard" allows for the creation of a learning community centered in the knowledge areas of PM. In many ways, an online course platform provides a useful learning area, whether the course is online or offline, acting as a virtual "war room" in which the students and professor can interact.

Palloff and Pratt (1999) provide a number of suggestions for managing an online course that will create a community of learners. A major point in the book is that interaction via the web is different from classroom interaction; it draws on different skills from both students and professor than face-to-face meetings in a classroom. An online course has a way of democratizing the class experience by emphasizing written communication skills as the primary vehicle of expression and by eliminating many social cues such as dress, physical appearance and body language. An online course also introduces delay in the communication process, a delay between when something is posted, when it is read, and when a response is posted. The major form of establishing that a communication has been heard is to post a response and if the discussion groups are not being updated several times a day with postings from students and the professor, there is a tendency for students to drop out of the conversation. The richness of face-to-face conversation has to be replaced with a rich version of a written conversation. Borich (2004) identified five classroom teaching strategies, namely direct instruction, indirect instruction, questioning strategies, self-directed learning and cooperative learning. These strategies can be adopted for online courses (Borich, 2004; Glass, 2006). Table 1 show these classroom teaching strategies with appropriate IT technology for possible use in an online teaching environment.

\begin{tabular}{|c|c|c|}
\hline How we learn... & Instructional Strategies & Online instructional tools \\
\hline We learn by listening. & $\begin{array}{l}\text { Direct Instruction and } \\
\text { Self-directed Instruction }\end{array}$ & $\begin{array}{l}\text { Online audio clips, audio PowerPoint, online } \\
\text { conferences }\end{array}$ \\
\hline We learn by seeing. & $\begin{array}{l}\text { Direct instruction and } \\
\text { Self-directed Instruction }\end{array}$ & $\begin{array}{l}\text { PowerPoint Slides, online video clips, } \\
\text { tutorials }\end{array}$ \\
\hline We learn by asking. & $\begin{array}{l}\text { Questioning Strategies } \\
\text { and Cooperative Learning }\end{array}$ & $\begin{array}{l}\text { Mentoring in Chat / E-mail / Threaded } \\
\text { discussion among students, and between } \\
\text { students and instructors and tutors. }\end{array}$ \\
\hline $\begin{array}{l}\text { We learn by exploring, } \\
\text { modeling, researching, } \\
\text { and practicing. }\end{array}$ & Experiential Learning & $\begin{array}{l}\text { Case study, simulations, computer-based } \\
\text { activities, hands-on activities, reflection } \\
\text { assignments }\end{array}$ \\
\hline We learn by reading. & Direct Instruction & $\begin{array}{l}\text { Instructor's lectures in notes, PowerPoint, } \\
\text { Word or PDF document format; articles, web } \\
\text { resources, textbook }\end{array}$ \\
\hline
\end{tabular}

Table 1. Teaching Strategies for Online Courses

Coppola et al. (2000) suggests that an important factor for effective online learning are high-quality and highly motivated students. At the beginning of an online course, the students should complete a self-assessment with an instrument such as the "Self Evaluation for Potential Online Students" published on the web by the Illinois Online Network. A self-assessment gives the student an opportunity to determine if online learning fits their circumstances, lifestyle, and educational needs. The questionnaire raises some basic issues to help the students decide if an online program is right for them. This survey also provides a professor with a self-assessment as to whether the instructor is comfortable with the activities necessary to deliver an online course. Some example 
questions are: Are you comfortable using technology? Are you comfortable communicating in writing? Are you self-motivated and self-disciplined?

The first component of an online course development methodology to consider is the environment (Coppola et al., 2000). In the online environment the "same time same place" meeting and work environment of the classroom is replaced by either a "different time different place", completely asynchronous, or a "same time different place", synchronous environment using web based collaborative presentation software possibly including online video or audio conferencing. This technology is also provided by many course management software applications. The preference of students and instructors on this issue are important.

The question of the effectiveness of teaching a PM course in a completely "asynchronous" environment is important. Courses that are mainly focused on "content" (terms, definitions, concepts and theory) are usually more suitable for this "asynchronous" environment. However, if the objective is also interaction among students and between students and professor to develop good interpersonal skills in communication, dialogue, leadership, management, and project teamwork, an "asynchronous" environment may not well support some types of activities such as presentations, meetings, interviews and questioning of team members about work status. Thus, different technologies were experimented to simulate "synchronous" environment in online courses including television technologies. Webster and Hackley (1997) presented several issues with using television technologies to synchronize in online courses and one was the feeling of being disconnected from the professor and classmates that reduced student attention. More current technologies in use today for synchronization are presented later in the paper.

In the proposed methodology "virtual" teamwork is recommended to replace the group and team projects normally assigned in a traditional offline PM class. The interactions of students between themselves and their instructor are necessary in a traditional PM class and are no less essential, although more difficult to accomplish, in an online environment. Students should be given an opportunity in an online course to gain valuable experience working with real virtual teams solving realistic problems.

An important issue for the methodology is how to package and deliver the course content. The content of a PM course can be partitioned into major topics along the lines of the Project Management Body of Knowledge (PMBOK) provided by Project Management Institute (PMI). Each module can cover a major topic from the PMBOK with the various topics linked together with various activities into a cohesive whole. Additional modules can be created on more specific topics such as Function Point analysis, Earned Value, PERT/CPM, GANTT Charts, and financial return on investment analyses just to name a few. The PM software such as MS Project can be divided into several modules, including an advanced module on how to best use and apply this software.

The guidelines for design and development of an online PM course start with prior research on best practices in teaching and learning, including some resent research on how to make the online learning environment more effective. The best practices in teaching include the following suggested by Frye, 2009. Engage students in active learning experiences; Set high, meaningful expectations; Provide, receive, and use regular, timely and specific feedback; Become aware of values, beliefs, preconceptions and unlearn, if necessary; Recognize and stretch student styles and developmental levels; Seek and present real-world applications; Understand and value criteria and methods for student assessment; Create opportunities for student-faculty interactions; Create opportunities for student-student interactions (critical questions and discussion groups) ; Promote student involvement through engaged time and quality effort.

Recently, more suggestions are made to improve learning in online courses. For example, Rossin et al. (2009) have shown a very positive effect of "flow" in an online course which is a psychological state associated with improvement in task performance and learning outcomes. The theory of flow suggests a better engagement of individuals and therefore more learning with tasks that are challenging. Individuals are more attentive, focused 
and able to concentrate on the task when they are in a state of flow. Csikszentmihaly (1988) identifies six dimensions to determine if a person is in fact in the flow while performing a task: focused concentration, margining of activity and awareness, perceived control, transformation of time, transcendence of self and autotelic experience. This shows the importance of flow in design and delivery of an online course such as PM to improve the learning outcomes. Students can be better engaged in the course by asking them to participate on discussion of different current topics and case analyses. They should be provided with constant feedback and direction. They should be challenged by asking them to work on multiple-part problems and running cases. They should be asked to work on problems requiring research. They should be asked to work on team projects. Finally, they should be encouraged to check the course site often for new activities and updates. Incentives and awards should be given in terms of credit points to further improve student engagements and interactions. Students should compete for these points. It is important to create an exciting environment with the online course such that students are eager to access the course site for work, interaction and feedback. A challenging environment should increase the effort and engagement and therefore, learning.

Kamis and Kahn (2009) present Kolb's (1976) learning cycle and Huber's (1980) problem solving approach and how they relate to effectively teaching students problem solving skills, and improving learning outcome. While Kolb is focusing on sequencing of problems, Huber is focusing on sequencing of steps within a single problem. The effective approach to use in PM is learning-by-doing, applying the concepts to solve real-world projects. Kamis and Kahn (2009) argue concrete problems are more demanding and thus more challenging, and suggest the sequence of concrete-abstract-concrete. This makes abstract problems easier when followed by the concrete problems. In general, individuals work harder when demanding work is expected (Foos, 1992), and they rise to a challenge. This relates well with the flow theory that students are more engaged and focused when they are challenged. Therefore, students should first be presented with concrete problems that require following step-bystep procedure and instructions. They should be given feedback, and the instructor should make sure they are on a right path to solve the problem. They should then be introduced to abstract problems and another set of concrete problems at the end of the course. In a PM course students should be presented with the concepts and be asked to work on a series of small projects with predetermined solutions. They then should be asked to work on a team project of their own and, possibly, some short cases. They should be presented with a few more small projects with predetermined solutions at the end to wrap up the course.

\section{LESSONS LEARNED AND BEST PRACTICES}

Following is a proposed outline encompassing best practices. This outline, which is not exhaustive, suggests activities for an online PM course, and can be tailored to suit a specific teaching style. Further, this outline is an attempt to compensate for some of the limitations of a completely asynchronous, "different time, different place" online courses. Some interaction among students and between the student and the instructor is planned and the students are given an opportunity to gain experience of working in virtual teams to solve real PM problems.

1. In general, course management software such as D2L (Desire To Learn), WebCT-Vista, and Blackboard provides features such as chat rooms, email, announcements, a calendar, assignments, assessments (online testing), discussions (blogs) and an easy interface for uploading files that are critical to this course.

2. The overall content of the course textbook and course material should be provided to the students in several forms online that is available during the entire term. This should include Power Point slides for each chapter (with and without audio), chapter summaries, lecture notes, video clips and review questions. Reading material and links to web based material should be provided in a folder on the course management software homepage. The online material is not sufficient to alleviate the need for the student to purchase and read a text book, however having the students pay for an online version of the text book would. Furthermore, a customized e-text should be considered to gather material from different sources to make the book comprehensive and to include the latest subjects and developments in the field of PM, such as agile and international PM. The e-book is also a less expensive alternative with the students having the option of 
purchasing the hardcopy of the customized book. In addition, the students should be provided with a relatively detailed schedule that requires them to stay current on a weekly basis, with reading and work assignments.

3. Most texts on the subject of PM adequately cover the subject's primary content, but many do not give adequate attention to leadership and soft management skills. In order to address this limitation, there are popular books, as listed below that can be used for additional student reading and study. These books fit and complement many PM textbooks greatly.

- Robert Austin, Nolan, O’Donnell, 2009, The Adventures of an IT Leader, Harvard Business Press, ISBN: 978-1-4221-4660-6

- Stephen Covey, 1994, First Things First, ISBN: 0-671-86441-6

- Stephen Covey, The 7 Habits of Highly Effective People, ISBN: 0-671-70863-5

- Stephen Covey, The 8th Habit: From Effectiveness to Greatness, ISBN-13: 9780743287937

- Eliyahu M. Goldratt, Critical Chain, The North River Press, 1997, ISBN 0-88427-153-6

- Patrick Lencioni, 2002, The Five Dysfunctions of a Team, Jossey-Bass, ISBN: 978-0-7879-6075-9

4. The assignments function of the course management software should be used to schedule and provide supporting descriptions and files for several problems, case analyses, simulations and team assignments. The specific due dates should be set up throughout the course period and kept up to date on the course management calendar.

5. A very important early assignment for each student is to complete and post a student profile or selfintroduction, which is made available to all students. This self-introduction provides information to facilitate forming teams. The students are asked to answer the following questions as they are introducing themselves to the class:

- Where are you from?

- What are your hobbies?

- What is your background, your undergraduate degree and institution?

- What are your skills?

- What interests you the most about technology?

- What kind of project would you like to work on?

- What can be your major contributions to a project?

- Have you worked in a virtual team?

- How familiar are you with collaboration and communication technologies?

- Can you sometimes meet face-to-face with your team?

- What are your career plans, Hobbies, out of school interests? (include five or more interesting facts about yourself)

- Please share anything else you want.

- Please attach a favorite photo of yourself (jpg or gif).

An important component of the PM course is working in a team project. It is important for team members to work well together, without much conflict, in order to be effective. Therefore, the students are asked to form their own team rather than the instructor making the assignments. An appropriate team size is determined to be three. The teams with four or five students usually have a greater conflict to work together. Students are asked to make sure their team has multiple talents, individuals with different capabilities and backgrounds including management/leadership, technical, and financial to contribute to the project. They are also reminded of compatibility in behavior and attitude. The students are provided with a site to determine their Myers-Briggs Type Indicator MBTI which should help them in forming teams. These are necessary for teams to be effective in carrying out a significant project. 
6. Each week the instructor should post (or have the students post) a discussion question (critical question) that all students are asked to address. This includes comments related to the subject posted as well as comments addressing issues raised by other students. This weekly discussion is asynchronous and is an attempt to allow students to learn from each other, something that is very important and can be achieved in a traditional classroom by open discussions. In addition, discussion of each chapter should be encouraged and included in the participation grade. The followings are suggestions for each chapter discussion.

- What interested you the most in this chapter?

- Anything related to this chapter that you have heard or read?

- Discuss applications of what is covered in this chapter in real life, work and project in this course.

- Share your experience related to what is covered in this chapter.

The students should be reminded that communication in an online environment takes special consideration. They should not use acronyms (text message abbreviations) unless they are understood by the recipient(s) of the message. They should be careful what they say to someone on the discussion tool because everyone in the class will see it, and it cannot be retracted. They students should be asked to abide by netiquette below when talking to other classmates.

- Be sensitive and reflective to what others are saying.

- Don't use all caps. It is the equivalent of screaming.

- Don't flame - These are outbursts of extreme emotion or opinion.

- Think before you hit the post (enter/reply) button. You can't take it back!

- Don't use offensive language.

- Use clear subject lines.

- Don't use abbreviations or acronyms unless the entire class knows them.

- Be forgiving. Anyone can make a mistake.

- Keep the dialogue collegial and professional.

7. The project teams should be asked to perform several specific assignments:

- After the teams are formed, one of the first assignments is for each team to develop a project plan, with a detailed schedule, Work Breakdown Structure (WBS), project charter, schedule (GANTT) chart and budget showing how the team is going to complete all of the course assignments during the semester. The class itself is an example of a project. The teams should also be given an assignment on preparing a proposal to make a case for their team project. The significance of the problem identified and why there is a need for a project to solve the problem, also why the project should be funded. They should generate different solution alternatives and apply financial analysis (payback, Return on Investment (ROI), Net Present Value (NPV) to compare them and show clearly their suggested solution is superior to other alternatives, and therefore their project should be fully funded. This should give them experience of writing project proposals and competing for scarce resources. The above suggestions can be organized into at least three milestones with specific guidelines for accomplishments and deliverables. The instructor should have an online meeting with each team providing them with inputs following each milestone before teams work on the next milestone.

- The teams are encouraged to work as a virtual team, minimizing face-to-face meetings. Some tools to support this are email, chat rooms, and ooVoo/Skype (free Voice over IP service), SharePoint, and Google Apps that can support participants in an audio conference.

- A team research project should be assigned, on a subject selected by the instructor, due at the end of the semester. The teams should be asked to prepare an online presentation on a subject assigned by the 
instructor. This can be as simple as the team posting Power Point slides (with or without audio) to a more complex audio/ video presentation. This is a rather inferior alternative to the traditional in-class team presentations used to teach communications skills. One way to improve on this would be to require the students to attend a virtual meeting online several times during the semester so that they could participate and be involved in the team presentations. Of course this would require establishing a specific time for such meetings at the beginning of the semester. In the Blackboard world of course management software, there is a product called "Wimba" which is very effective for live student presentations, group discussions, review for exams and guest-speaker presentations. The instructor should meet with each team periodically in Wimba to receive a progress report and provide feedback. For example, after each team has completed a milestone and has submitted milestone deliverables. The "Adobe Connect" is also a good alternative which provides the ability to meet "live" online with students. The Adobe Connect is a companion product, which can be used in conjunction other course management software

- A Case can be used as an ongoing project during semester that requires the team to plan, organize, direct, control and close the project, and provide the appropriate documentation during each phase of the project.

8. Each student should be provided with a demonstration copy of the software, such as Micro Soft (MS) Project used in the course. This software should also be available in the computer labs on campus. They are expected to learn how to use and apply the software on their own using the tutorial/Help and training material. A textbook on the software should also be recommended to them. The teams should be asked to use the software in planning, tracking and controlling both the course project as well as the ongoing case project. In addition, the students should be exposed to SAP Project System (PS) as increasingly more companies are using ERP/SAP (Enterprise Resource Planning/Applications and Products in Data Processing. A few assignments using SAP PS will be beneficial following their learning and understanding of a software such as MS Project. A list of recommended books to students is provided below.

- Rachel Biheller Bunin, New Perspectives on Microsoft Project 2010, 2012, Course Technology.

- Mario Franz, Project Management with SAP Project System, Second Edition, 2010, SAP Press

- Carey Cole, Fox, Kroenke, SharePoint for Students, 2012, Prentice Hall

- A Guide to Project Management Body of Knowledge (PMBOK GUIDE), 2008, Fifth Edition, Project Management Institute

9. Project Management Simulation is a good way to wrap up the course. For example, Scope, Resources, Schedule by Robert D. Austin, 2013, Harvard Business Publishing which takes 90 minutes to complete and there is a small access fee to be paid online and it is good for one year of access. The students can work with the six scenarios provided or customized by the instructor. The scenarios can be repeated to improve performance. The instructor is provided with a complete analysis of each student performance. The following Description, Learning Objectives, and Subject Covered are provided by Harvard Business Publishing about the simulation.

\section{Description:}

In this single-player simulation, students take on the role of a senior project manager and manage a team tasked with developing a new product for an electronics manufacturing company. The primary objective is to execute a project plan successfully and deliver a competitive product on time and on budget. Students are exposed to realistic challenges that project managers often face, especially when working in a highly competitive industry. Some challenges require students to react to unanticipated outside events, such as a staffing crisis, while others require students to respond to strategic changes mandated by upper management. A new project lever for specifying prototypes allows students to explore the benefits of this essential component of agile project management.

Learning Objectives: 
- Explores trade-offs among the 3 major project management levers: scope, resources, and schedule

- Illustrates importance of and trade-offs associated with level, timing and type of communication

- Shows the value of coaching and training

- Examines importance of team member morale on productivity

- Aids in illustrating the concept of earned value management

- Highlights importance of appropriately timing changes in project resource allocation

- Forces to navigate projects through uncertainty and unanticipated events

- Illustrates the concept that correcting problems early in the course of the project provides significant benefit

\section{Subjects Covered:}

Budgets; Leading teams; Managing people; Project management; Prototypes; Resources

10. At random intervals throughout the semester the students should be given online quizzes on the contents of the material in the text to encourage them to stay current with their reading assignments. These quizzes are open for a specific duration and are timed, making it difficult for the student to look up the answers in the text.

\section{DISCUSSION}

The author has been teaching graduate and undergraduate PM Courses in traditional mode of delivery for many years and recently teaching this course online using different course management software for online delivery. The author was somewhat skeptical that a PM course could be effectively delivered online when first starting to design this course online. This skepticism was supported by research finding (Tanner, Noser, \& Totaro, 2009) focusing on perception, and comparing faculty and student assessment of online learning that faculty are less inclined to want to teach an online class than students are inclined to want to take them. It was very clear from the start that the design of online PM course will be different than teaching it offline. This is particularly true because of significant teamwork activities involved in a PM course and therefore, it was a challenge to have students who have never met form and build their teams, spend significant amount of time interacting using communication technologies with no experience, and propose and complete a project successfully on time and within budget. This teamwork activity is quite a challenge in a traditional classroom and even more of a challenge online.

A comparison of students' performance between the traditional class and the online class was performed. The students' performance was assessed similarly between the online PM course and the classroom version of the course. The same assessment tools were used in both online and offline classes and the workload in the two classes was comparable.

The students were inquired about their experience in the course at the end of the semester. The most often expressed positive factor was the increased flexibility, and convenience of online courses, followed by the ability to learn at your own pace and the ability to access course content anytime, anywhere. The most significant and often expressed negative factor was teamwork issues. For example, issues related to teamwork salient to participants were coordination, cooperation, collaboration and communication. Other factors cited often by the students were effective interaction with professor and others, including team-members, discussion, which can also be related to teamwork. This is not surprising since in a PM course, teamwork is very important. Table 2 presents the students primary negative factors which were mostly cited of an online PM related to teamwork, discussion and interaction. Table 3 presents the students secondary factors also cited as being negative factors of an online PM course. For example, some participants expressed the view that the online course gave them less exposure and less of an opportunity to learn from the professor's personal professional experience. 
- Teamwork issues (coordination, communication)

- Hard for team members to coordinate when not everyone is locally available

- Virtual teams could be hard to manage/coordinate with at times, that was the biggest issue

- Term projects can be a challenge

- More difficult for teams to synergize

- Professor and team member accessibility

- Hard for every team member to coordinate with sponsor

- Audio/Visual conferencing technology not very good

- Poor communication

- Communication, no teacher interaction

- Communication problems, more difficult to learn what is expected

- Hard to communicate effectively

- It is hard to create an online conference because usually the team consists of $4-5$ studying plus working adults, so once again the communication is delayed greatly.

- Having to wait to hear back about issues from students or teachers

- It takes time to get a response from the professor

- Hard to meet with team members, communication problems

- Hard to Communicate and hard to keep up with due dates

- There is always a way to ask the instructor online but the time spent on this process is also increased, as most of the communication is TYPE / READ instead of TELL / OBSERVE+LISTEN

- Limited interface with professors

- Less ability to learn from others (less interaction)

- Did not get to have face to face interaction with the professor

- Lack of personal interaction

- I prefer human contact and interaction, just a personal preference

- Less effective class discussions

- Lack of participation

Table 2 - Primary Negative Factors of Online PM Course 
- Tendency to procrastinate

- Problems with course management software

- Less exposure to professor's personal professional project management experience

- No formal lecture

- Some aspects may have been easier to understand in class setting

- This is not one of the courses that should be taught online. It should be taught in the classroom

- you must be highly self-motivated

- I think all the graduate courses should be taught live

- Presentations would be more effective in person

- The online course should be an exception for situations like mine as I had to choose between missing a semester and taking online course (military, sailors, people who has to travel a lot such as external representatives, etc.)

- More work, less instruction

- Online classes are also impersonal

- The workload was tiresome and overkill

- I have learned that there are far more assignments to be done with an online course

- Personal experience constitutes that time spent in online course is triple the time spent in regular course

- Difficult to learn math or more problem based material

- Have to learn on your own, workload can be too much

- Good time management skills required

Table 3 - Secondary Negative Factors of Online PM Course

The students' negative primary and secondary factors of online PM course support the notion that planning for an online course is substantially different than an offline course, and the instructors concern of effective teamwork and virtual team activities in the course. The online students clearly had problems communicating and interacting using technologies which might suggest teamwork in online PM courses may not be as effective as traditional classroom PM courses. The students often experience difficulty working as a team even when face-to-face meetings are possible. Adding the requirement for virtual teams significantly complicated the course. Many of the teams had problems cooperating, collaborating, communicating and coordinating their work. Students were dropping the course due to team problems (the online course had about a $20 \%$ drop rate compared to $5 \%$ for traditional graduate classes). Hence, one should not assume methods used traditionally in-class to form the teams for teamwork would be effective online.

In retrospect, to expect students to know how to work in virtual teams was an unreasonable expectation. Individuals who have experience working in face-to-face teams still have problems when they switch to a virtual environment. In developing a PM course, an important component must be to facilitate the process of forming and working together in virtual teams. The quality of online courses can be improved by structuring the course to use communication technology to support audio/video teleconferencing (Glass, 2006). The course management software has a "Live Classroom" function which allows instructors to add interactive lectures to their courses creating a "classroom" feel to any online course. This function includes full audio, video and chat capabilities, as well as power point presentations and a whiteboard. However, from the instructors' experience, the video component does not always work and the quality and reliability of the audio is not always acceptable. Many attempts to hold a live classroom meeting and team presentations have failed. One should expect that not all students attend, some who sign on cannot be heard and some cannot hear the instructor. Therefore, one should not assume the reliability of technology all the time, and they should be required to check and test all their equipment for functionality ahead of time. The students should be provided with guidelines for this test and ask them to run a wizard to make sure everything is in proper order well in advance of the meetings. They should be 
told clearly at the beginning of the semester of the hardware and software requirements and to expect some failures.

The teams should be asked to prepare audio power point presentations to upload to the course management software, so it can be made available to all students as a backup plan. One possible problem with this approach is often large size of the audio files. Another lesson learned is that any attempt at conferencing (chat, discussion groups, audio and or video) should be limited to small groups and trying to conference or use the course management software discussion feature with a large class is problematic. A good practice is to have online meetings with each team separately.

An online discussion needs to be facilitated, and the students should be encouraged to participate. The participation and discussion should be graded and expectations should be defined. The students should be provided with a checklist and rubric for discussion expectations and how they will be graded. The students should also be encouraged to follow netiquette which is a set of rules for online communication. A list of netiquette rules should be provided to students.

Asynchronous learning is preferred by students, "anywhere, anytime learning." The asynchronous discussions have many advantages as students will spend more time thinking and reflecting about what to say and sometimes they do research before responding. This should help improve learning as opposed to classroom setting that they have to respond quickly before moving on to another topic. Further, the students can participate without being in one place and time.

The need for the development of a methodology is clear to successfully offer an effective online PM course. In addition to suggested components for this methodology, the comments of students are given on their experience. Therefore, the following should be considered and included for a methodology to be effective.

- Students want the added flexibility of taking classes online, especially in graduate programs. Student experiences with online courses have basically been positive.

- Project Management presents a special set of problems for an effective online course because of the need to teach skills related to communications, dialogue, critical thinking, interpersonal skills, team building and teamwork

- Teaching strategies for an online PM course should incorporate a modular approach to content delivery along with the following:

- Online audio clips, audio Power Point, online conferences (audio and /or video). The course should not be completely asynchronous.

- Online video clips, tutorials, as needed.

- Constant mentoring in Chat/E-mail/Threaded discussion among students, and between students, instructors and tutors needed.

- Case studies, simulations, computer-based activities, hands-on activities, realistic team projects and online team presentations.

○ Online audio clips, audio Power Point, online conferences (audio and /or video). The course should not

- Instructor's lectures in notes, syllabus, Power Point slides, Word or PDF document format; articles, web resources, textbook

- Teaching students how to form and effectively work in a virtual team environment.

\section{CONCLUSIONS, LIMITATIONS, AND FUTURE WORK}

The purpose of this research is to discuss somewhat the differences between teaching PM course in an online environment as opposed to a traditional classroom. This research presents the challenges associated with teaching 
an online PM course and identifies the components of a methodology for designing and delivering an effective online project management course. In addition, comments of students are given at the completion of the course.

Although, there are differences in the design and delivery, but learning outcome seems to be the same. The goal and objectives of the course can be mostly met in either an online or traditional class environment and students seem to be learning the same in both environments. However, it seems designing an online PM course is more time-consuming and challenging. This is particularly true about teamwork and virtual teams, which is a main component of a PM course. The endeavors of planning and designing an online PM course including teamwork and virtual team will be facilitated with the advancement of technology and as both instructors and students gain more experience with online teaching and learning.

Overall, the students seem to like the increased flexibility of online courses, but they do think they are at a disadvantage because of the lack of face-to-face interaction with the professor and other students. A question often asked is whether it is easier to prepare and teach an online course compared with a traditional course. The design and preparation for an online PM course is much more challenging and time consuming based on experience. At a minimum the amount of time spent with the online course is at least $150 \%$ of the time spent on the traditional in-class course.

There is some agreement with other research in the area of online courses and the findings of this study which lends it some validity, and therefore, empirical research stream is needed to further validate the suggestions of this study. The empirical evidence is the limitation of this study and the findings are based on the literature, best practices and the experience of the instructors teaching project management. Also, more research is needed toward development of a methodology to effectively offer an online PM course. More components of this methodology should be identified in addition to the components presented in this research. The methodology and its components should be tested.

Graduate and undergraduate students and faculty members from different institutions with experience teaching online PM courses need to be surveyed to learn more about the issues to be addressed and the components to be added to the methodology. The factors for increased drop rate in the online PM courses should further be examined. A comparison of findings with online and offline PM courses offered in other counties should also be interesting.

Moreover, research is needed to explore the impact of the flow theory on learning outcomes. It appears that the flow theory provides an added value to engage and involve the students to increase learning. Encouraging and challenging students should increase their involvement and participation which consequently should result in more learning. Finally, research is needed to investigate the sequence of concrete-abstract-concrete presentation of problems to students.

\section{REFERENCES AND CITATIONS}

1. Ambient Insight. (2009). Innovation in Educational Technology: The Virtualization of K-12 and Higher Education.

2. Austin, R. (2009). Project Management Simulation: Scope, Resources, Schedule. Harvard Business Publishing. Retrieved from http://cb.hbsp.harvard.edu/cb/access/12120418.

3. Aggarwal, A., \& Bento, R. (2000). Web-based education, In A. Aggarwal (Ed.), Web-based learning and teaching technologies: Opportunities and challenges (Vol. 20, p. 153). Hershey, PA: Idea Group.

4. Allen, I. E., \& Seaman, J. (2006). Making the Grade: Online Education in the United States, 2006. The Sloan Consortium.

5. Allen, I.E. \& Seaman, J. (2011). Going the Distance: Online Education in the United States 2011, Babson Survey Research Group. Retrieved 11/15/11 from, 
http://sloanconsortium.org/publications/survey/going_distance_2011.Bagnato, K. (2004, May 10). Learning virtually. Community College Week, 6-8.

6. Bagnato, K. (2004, May 10). Learning virtually. Community College Week, 6-8.

7. Bernard, R.M., Abrami, P, Lou, Y., \& Borokhovski, E. (2004), "How Does Distance Education Compare With Classroom Instruction? A Meta-Analysis of the Empirical Literature." Review of Educational Research, Vol. 74, No. 3, pp. 379-439. http://dx.doi.org/10.3102/00346543074003379

8. Bisoux, T. (2002). The E-learning equation. BizEd, 22-29.

9. Borich, G.D. (2004), Effective Teaching Methods (5th Ed.). Upper Saddle River, NJ: Pearson.

10. Chaos Report. (1995). The Standish Group Report. Retrieved from http://net.educause.edu/ir/library/pdf/NCP08083B.pdf.

11. Campbell, C. (2004, March 11). Remote piano lessons, in real time. New York Times.

12. Cobb, A. (1980). Informal influence in the formal organization: perceived sources of power among work unit peers. The Academy of Management Journal, 23(1), 155-161.

http://dx.doi.org/10.2307/255503

13. Coppola, N. W., Hiltz, S. R., \& Rotter, N. G. (2000). Becoming a virtual professor: Pedagogical roles and asynchronous learning networks. Journal of Management Information Systems, 18(4), 169-189.

14. Csikszentmihihalyi, M. (1988). The Flow Experience and Its Significance for Human Psychology. In M. Csikszentmihihalyi and I. Csikszentmihihalyi (Eds.), Optimal Experience: Psychological Studies of Flow in Consciousness (pp. 15-35). Cambridge: Cambridge University Press.

http://dx.doi.org/10.1017/CBO9780511621956.002

15. Dolezalek, H. (2004). The state of the e-learning market. Training, 41(9), 20-28.

16. Ellin, A. (2000, August 6). Online teaching; the battle in cyberspace. New York Times.

17. Foos, P.W. (1992). Test Performance as a Function of Expected Form and Difficulty. Journal of Experimental Education, 60(3), 205-211.

http://dx.doi.org/10.1080/00220973.1992.9943876

18. Frye, R. (2009). Focus on student learning outcomes. Office of Institutional Assessment, Western Washington University, Retrieved from http://pandora.cii.wwu.edu/cii/resources/outcomes/best_practices.asp

19. Glass, R. L. (2006). The Standish report: does it really describe a software crisis? Communications of the ACM, 49(8), 15-16.

http://dx.doi.org/10.1145/1145287.1145301

20. Granitz, N., \& Greene, C.S. (2003). Applying e-marketing strategies to online distance learning. Journal of Marketing Education, 25, 208-225. http://dx.doi.org/10.1177/0273475302250569

21. Hezel Associates. (2005). Global e-learning opportunity for U.S. Higher Education. Hezel Associates, LLC.

22. Hollenbeck, C. R., Zinkhan, G. M., \& French, W. (2005). Distance learning trends and benchmarks: Lesson Learned from an online MBA program. Marketing Education Review, 15(2), 39-52.

23. Howard, J. (2002). Do College Students Participate More in Discussion in Traditional Delivery Courses or in Interactive Telecourses? A Preliminary Comparison. The Journal of Higher Education, 73, 764-780.

http://dx.doi.org/10.1353/jhe.2002.0052

24. Huber, G. P. (1980). Managerial Decision Making. Scott Foreman \& Co. 
25. Illinois Online Network. Self Evaluation for Potential Online Students. University of Illinois. Retrieved from www.ion.uillinois.edu/resources/tutorials/pedagogy/selfEval.asp.

26. Kamis, A., \& Kahn, B. K. (2009). Synthesizing Huber's Problem Solving and Kolb's Learning Cycle: A Balanced Approach to Technical Problem. Journal of Information Systems Education, 20(1), 99-111.

27. Kohlmeyer, J. M., Seese, L. P., \& Sincich, T. (2011), “Online Versus Traditional Accounting Degrees: Perceptions of Public Accounting Professionals," in Anthony H. Catanach, Dorothy Feldmann (ed.) Advances in Accounting Education: Teaching and Curriculum Innovations (Advances in Accounting Education, Vol. 12), Emerald Group Publishing Limited, pp.139-165.

http://dx.doi.org/10.1108/S1085-4622(2011)0000012009

28. Kolb, D. A. (1976). Management and the Learning Process. California Management review, 18(3), 21-31. http://dx.doi.org/10.2307/41164649

29. Metrejean, E., \& Noland, T. (2011), “An Analysis of CPA Firm Recruiters' Perceptions of Online Masters of Accounting Degrees,” Journal of Education for Business, Vol. 86, No. 1, pp. 25-30.

http://dx.doi.org/10.1080/08832321003713754

30. Murphy, K. L., \& Cifunentes, L. (2002). Using web tools, collaborating, and learning online. Distance Education, 22(2), 285-305.

http://dx.doi.org/10.1080/0158791010220207

31. Myers-Briggs Type Indicator. Retrieved from www.goddessflight.com/per/passess.htm.

32. Palloff, R. M., \& Pratt, K. (1999). Building learning communities in cyberspace: effective strategies for the online classroom. San Francisco, CA: Jossey-Bass Publishers.

33. Peltier, R., Schibrowsky, J., \& Drago, W. (2007). The interdependence of the factors influencing the perceived quality of the online learning experience: a causal model. Journal of Marketing Education, 29(2), 140-153.

http://dx.doi.org/10.1177/0273475307302016

34. Piccoli, G., Ahmad, R., \& Ives, B. (2001). Web-based virtual learning environments: a research framework and a preliminary assessment of effectiveness in basic IT skills training. MIS Quarterly, 25(4), 401-426.

http://dx.doi.org/10.2307/3250989

35. Privateer, P. (1999). Academic Technology and the Future of Higher Education Strategic Paths Taken and Not Taken. The Journal of Higher Education, 70(1), 60-79.

http://dx.doi.org/10.2307/2649118

36. Rossin, D., Ro, Y. K., Klein, B. D., \& Yi, M. G. (2009). The Effects of Flow on Learning Outcomes in an Information Management Course. Journal of Information Systems Education, 20(1), 87-96.

37. Sahin, S. (2006), "Overcoming the "No Significant Difference" Phenomenon in Distance Education by Internet." Retrieved 10/16/2010 from http://www.aof.edu.tr/iodl2006/

38. Scardamalia, M., \& Bereiter, C. (2006). Knowledge building: Theory, pedagogy, and technology. In K. Sawyer (Ed.), Cambridge Handbook of the Learning Sciences (pp. 97-118). New York: Cambridge University Press.

39. Smith, L. (2001). Content and delivery: a comparison and contrast of electronic and traditional MBA marketing planning courses. Journal of Marketing Education, 23(1), 35-43.

http://dx.doi.org/10.1177/0273475301231005

40. Tabatabaei, M., \& Gardiner, M. (2012). Recruiters' Perceptions of Information Systems Graduates with Traditional and Online Education, Journal of Information Systems Education, 23(2), 133-141. 
41. Tallent-Runnels, M.k. et al. (2006). Teaching Courses Online: A Review of the Research. Review of Educational Research, 76, 93.

http://dx.doi.org/10.3102/00346543076001093

42. Tanner, J. R., Noser, T. C., \& Totaro, M. W. (2009). Business faculty and Undergraduate Students' Perceptions of Online Learning: A Comparative Study. Journal of Information Systems Education, 20(1), 2940.

http://dx.doi.org/10.2307/257034

43. Webster, J., \& Hackley, P. (1997). Teaching effectiveness in technology-mediated distance learning. The Academy of Management Journal, 40(6), 1282-1309. 